\title{
O Lugar do Corpo e da Subjetividade do Portador de Epilepsia
}

The place of the body and of the subjectivity of the bearer of epilepsy

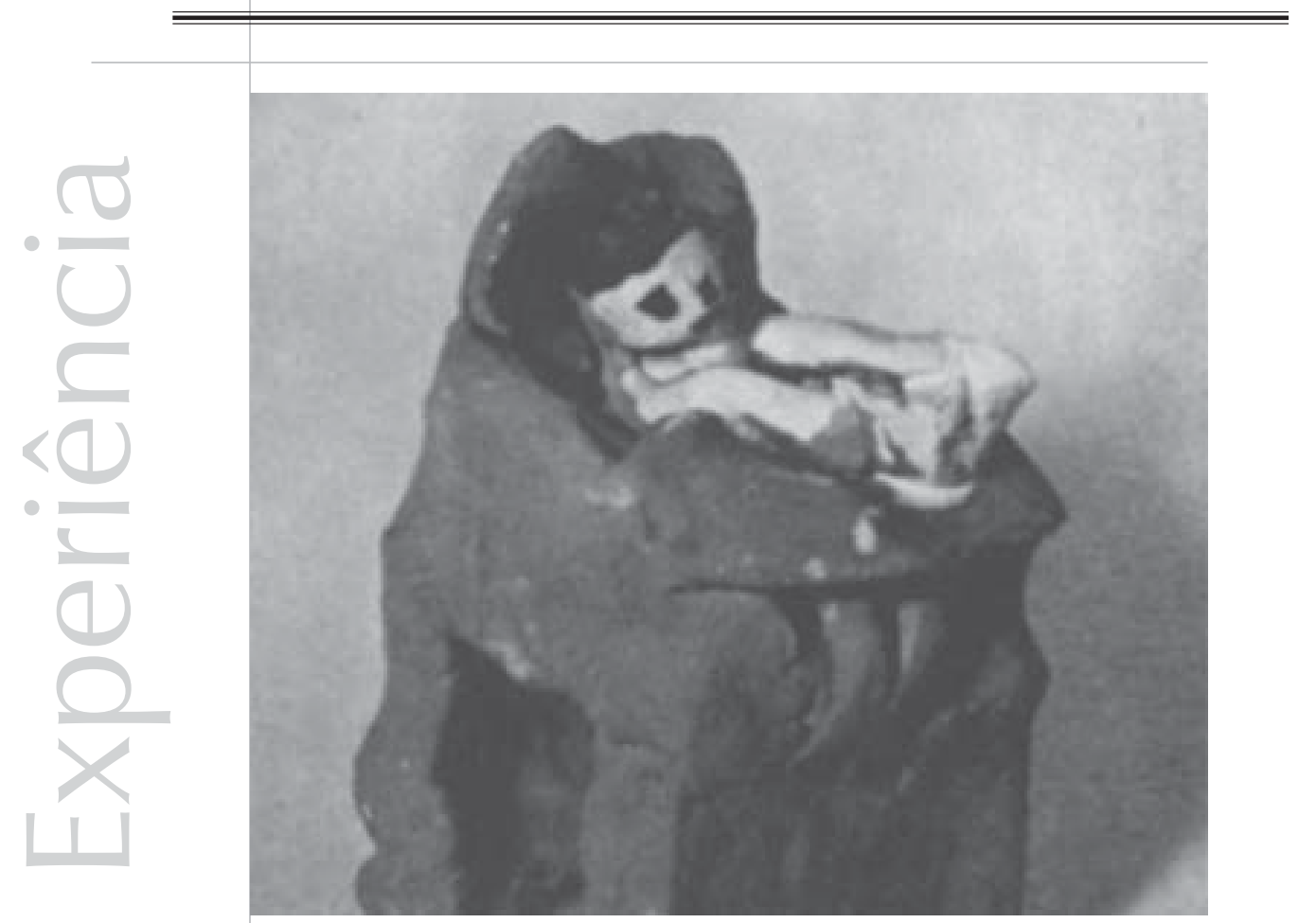


Resumo:Este depoimento representa mais uma lição de vida que um estudo teórico. Os três anos de trabalho voluntário na Associação dos Portadores de Epilepsia de Minas Gerais me permitiram conhecer e assistir a alguns portadores e ex-portadores de epilepsia e suas histórias, permeadas pelo sofrimento e pela esperança. Hoje, sabe-se que a epilepsia ainda não possui uma definição satisfatória que nomeie a sua etiologia. Considerada como sintoma, ela apresenta um amplo e complexo quadro de crises. O sofrimento desse sujeito revela formas de subjetivação alicerçadas na impotência. Tal sentimento revela um pedido de acolhimento e respeito por parte da sociedade.

Palavras-chave: epilepsia, psicanálise, subjetividade, cidadania.

Abstract:This paper is related to a life experience and not only a theorical study. During three years of work as a voluntier at the Associação dos Epilépticos de Minas Gerais (Epilepsy Association of MG) I was allowed to meet some patients and ex-patients and to know their stories and hopes. Up to now, epilepsy does not have a satisfatory etiology. Considered as a symptom, it is very complex and causes crises and attacks. This suffering revels subjectivation that implies pain and fellings of impotence that should be respected by the whole society.

Key-words: epilepsy, psychoanalisys, subject, citizenship.

O assunto exposto neste relato de experiência significa uma pequena proposta de estudo para a posteridade. Na verdade, compreende uma contribuição para aquilo que, adiante, possa vir a tornar-se uma grande pesquisa. A epilepsia é, hoje, uma doença muito pouco explorada pela Psicologia e pela psicanálise. No Brasil, somente depois da década de 40, estudos mais sistematizados puderam ser realizados com os avanços da Medicina e, agora, podemos dar início, sob a luz da psicanálise, a um discurso sobre o lugar desse sujeito epiléptico. Aqui, encontraremos algumas reflexões sobre o lugar desse corpo-sujeito e de sua subjetividade, apesar da marca da doença, a partir de uma experiência voluntária realizada em campo.

Julho de 1999. Recém-chegada a Juiz de Fora, conheci uma pessoa que passou a contarme sobre sua vida toda vez que nos encontrávamos, num lugar não muito apropriado. Sem muito entender, a princípio, os relatos sobre a sua doença vencida, reservei-me a escutá-la, simplesmente. Com muitos outros encontros, esses depoimentos se repetiram sucessivamente e começaram a apontar um caminho novo e desconhecido, o dos chamados portadores de epilepsia. A partir de então, em outubro de 1999, iniciei o meu trabalho voluntário na Associação dos Portadores de Epilepsia de Minas Gerais. As reuniões aconteciam uma vez por mês, e o seu teor girava em torno do apoio mútuo assim como da busca de informações e da idealização de cura. Todos os que procuravam a associação estavam, de uma certa forma, tentando aliviar os sofrimentos através de um possível milagre.

As primeiras reuniões a que assisti levaramme a perceber o objetivo de meu trabalho voluntário. Nada coincidiria com as necessidades dos associados naquele momento se me propusesse a realizar um 
trabalho de grupo com enquadramento clínico baseado em algumas das técnicas psicoterápicas conhecidas. Tal trabalho estaria condenado ao fracasso por completo, com tal proposta. Não havia nenhuma referência de trabalho desse tipo em que pudesse me inspirar. Angustiada, senti-me sozinha. Talvez essa angústia tenha sido necessária para que se pudesse seguir em frente com os propósitos imaginados. A epilepsia era algo desconhecido e cortinado por um tabu. Esse tabu existia não só no sujeito portador como também no seu meio familiar e em alguns profissionais, que a colocavam como uma impossibilidade. "Mas impossibilidade de que?" - Pensei. Foi daí que comecei a articular, tentando contextualizar e inferir o saber psicanalítico nessa impossibilidade.

Apesar do grande impasse diante do qual me encontrava, pude amadurecer ao deparar-me com essas novas e desconhecidas questões. O impasse envolvia a maneira pela qual articularia o conhecimento da epilepsia por parte da ciência e o que a psicanálise poderia dizer. Tudo aquilo que se sabia da doença sob o ponto de vista biológico-orgânico e o que não se sabia enquanto pessoas desejantes e faltantes, era-me desconhecido. Isso também levou-me a questionar se seria cabível utilizar-me dos procedimentos rigorosos da clínica, e se isso iria de encontro às demandas deles ou de encontro à minha proposta profissional. Afinal de contas, ninguém havia pedido para eu estar lá. Eu havia ido lá para escutá-los.

Foi difícil pensar e agir dentro de um grupo tão heterogêneo e fugaz. Além disso, estavam permeados por dois sentimentos paradoxais bastante complexos: por um lado, o sofrimento pela doença, e, por outro, a esperança de libertação. Acreditava que, a princípio, poderia existir uma impossibilidade de reflexão e de sensibilização pela via do trabalho grupal. Havia coisas que não poderiam ser analisáveis, mas existia a possibilidade de se construir um novo tipo de vínculo para que um estudo futuro se realizasse, abrindo portas para os outros profissionais. O desafio que me cerceava levou-me a romper com essa fantasia de onipotência profissional. Então, surgiu um trabalho possivel, onde foi estabelecido um vínculo novo com os sujeitos desse grupo. Iniciei a minha escuta com eles, sujeitos desse grupo, e não a escuta do grupo como um todo. O meu objetivo circunscreveu-se em conhecê-los, sem o compromisso do enquadramento clínico. No entanto, vale ressaltar que a ética e a cidadania nortearam o tempo todo o trabalho social que se configurava.

A escuta fluía de maneira a colocar-me entre eles, e não com eles, como acontece na clínica tradicional. A escuta permitiu-me espiar pela cortina os registros mais delicados e marcantes de suas vidas. Às vezes, as reuniões revelavam formas embrutecidas de pensamentos e sentimentos. A condição de menos valia a que se encontravam submetidos parecia um processo irreversível e assustador por causa das limitações da doença. Talvez, nessas limitações, estivesse o sentido da impossibilidade de viver. O que restava dessa condição, segundo alguns relatos, eram os inúmeros impedimentos, principalmente o impedimento de ser livre. Talvez esse impedimento representasse o único lado da vida que conheciam. Perguntava-me como um portador, depois de quase uma vida inteira de crises, ou de uma infância quase perdida ou de uma adolescência não vivida na sua plenitude, poderia viver e não somente sobreviver à epilepsia? O que seria ela, afinal? Que marcas ela deixaria no seu corpo e em sua subjetividade? 
Apresentando, em linhas gerais, o seu conteúdo nos moldes da neurociência, a epilepsia tem sua etiologia desconhecida (Guerreiro, 2000) e não possui uma definição satisfatória para ser considerada doença específica ou mesmo uma síndrome. As pessoas portadoras podem sentir vários sintomas e estes se configurarem de maneira complexa. As crises compreendem eventos clínicos originados no cérebro e estas, em suas características e formas, dependem das regiões cerebrais envolvidas na disfunção, ou seja, o sujeito, na crise, recebe descargas elétricas excessivas no cérebro a ponto de ausentar-se temporariamente e assujeitar-se, dentre outros, aos movimentos involuntários, às alterações da consciência e à confusão mental que essas agruras lhes trazem. Para aqueles que sofrem, os relatos ouvidos carregavam um pesar, pois acreditavam-se eternamente condenados por esse tempo de crise.

O diagnóstico de epilepsia coloca o sujeito dependente de um outro, seja familiar ou não, para que as suas crises sejam registradas. A partir daí, o seu destino, já fadado pelo horroroso constrangimento, passa a ter mais um adicional estranho e invasivo nessa história, o outro. Interessante pensarmos o quão paradoxal pode representar a condição de dependência de um outro, ao mesmo tempo em que esta última sinaliza um desamparo vivenciado por esse sujeito. O que esse outro significará em sua história de dependência e desamparo? Observamos e incluímos a família como referencial primário desse outro, pois é ela que acolhe ou não esses momentos aflitivos. Como o portador, a família se vê diante de um enigma, algo que não pode ser traduzido em palavras. É até difícil escrever sobre esse tema, pois as palavras fogem quando se quer traduzir o sofrimento do outro. Algumas famílias chegavam às reuniões com um duplo pesar, a de ver seu parente em sofrimento e sofrer por ser incapaz de ajudá-lo. Algumas desistiam da luta e incorporavam a doença como extensão de seus próprios corpos e desejos, afastando-se do caminho da cura.

Um ponto importante surgiu diante desse quadro. Tornou-se uma situação ímpar conhecer qual seria o lugar do corpo e da subjetividade do sujeito epiléptico, uma vez que não só a palavra se impunha ao corpo mas também o próprio organismo já estava condenado por si mesmo. Essa reflexão pode levar a amplas e complexas articulações teóricas e clínicas; no entanto, não pretendo, aqui, desenvolver profundamente essas proposições, mas apenas indicar alguns pontos nodais que necessitam ser discutidos. Voltando à questão, como o sujeito organizaria a sua subjetividade a partir de um corpo marcado não só pela palavra, mas também pelo organismo?

Compreendendo Freud (1979a), primeiramente, o corpo marcaria o eu e esse eu seria a projeção desse corpo sexual e pulsional e, num segundo momento, esse corpo seria destino daquilo que a força pulsional e o outro indicassem no registro originário do sujeito (Birman, 2001). Essa força pulsional seria a fronteira entre o mental e o somático como exigência feita à mente no sentido de ela trabalhar em ligação com o corpo (Freud: 1979c) e esse corpo representaríamos como marcas simbólicas. Isso quer dizer que pressão e finalidade da pulsão, no epiléptico, implicariam a força motriz, base para a sua subjetividade. $\mathrm{O}$ corpo supõe-se mergulhado no organismo presente e submetido a interferências da sua natureza. O curto-circuito, por causa das descargas elétricas, revelaria isso. O corpo pulsional se configuraria a partir de um
Interessante pensarmos o quão paradoxal pode representar a condição de dependência de um outro, ao mesmo tempo em que esta última sinaliza um desamparo vivenciado por esse sujeito. 
Enquanto a

medicação impõe ao sujeito uma

submissão a outros sintomas que potencializam os inúmeros conflitos, fragmentando a sua subjetividade, a cirurgia tem sido a chave para que esses conflitos sejam libertadose ressignificados. "aprisionamento" do desejo do sujeito marcado pelo orgânico. O objeto da pulsão, que conhecemos como não determinado, estaria indefinido mais ainda nesse sujeitosintoma. Vale ressaltar, também, que, em meio a algumas definições do sujeito pósmoderno, o sujeito epilético não se enquadraria como aquele do espetáculo e do narcisismo, como nos diz Joel Birman em seu livro O Mal-estar na Atualidade (2001), mas aquele excluído, como muitos outros, que estariam ausentes no ato de pensar e agir da comunidade. Talvez surja, daí, mais um novo contraponto para acrescentar aos ressignificados do mal do homem pósmoderno: o contraponto da exclusão. Muitos fazem, daquele que é diferente, que não se enquadra nos moldes de uma sociedade capitalista, o excluído. Mesmo sabendo que todos nós somos diferentes, o epiléptico possui mais um detalhe, o do aprisionamento biológico marcando a organização de sua subjetividade desde a sua origem.

Os epilépticos são um grupo esquecido, com nenhuma atenção dada às suas características subjetivas na contemporaneidade. Estamos falando muito pouco dos deficientes físicos e portadores de síndromes em articulação com o saber psicanalítico.

A epilepsia não se caracteriza enquanto enfermidade de que se possa subtrair a medicação. Infelizmente, esse é um dos caminhos que esse grupo tem para que a sua perturbação de espírito seja amortecida, ou pelo menos, para que as crises sejam inibidas. Por outro lado, pagam um preço muito alto pelo controle das crises, somando novos sintomas aos já conhecidos. Sabe-se que o uso da medicação, em algumas enfermidades da alma, está muito associado a uma estimulação exagerada ao consumo em virtude de uma economia altamente capitalista. O remédio está sendo utilizado para sanar não só os sintomas mas também a etiologia das patologias. As patologias de ontem são apontadas como sintomas e, conforme o contexto, adquirem novas roupagens a cada dia. As suas curas são promessas de "santos remédios". No entanto, para o epiléptico, o uso da medicação não representaria uma satisfação substitutiva para os seus conflitos, uma vez que ela também vem funcionar como peça importante na operacionalização de seu tratamento. O controle da crise poderá ser feito ou pela medicação ou pela cirurgia, e não só pela análise. Talvez a análise surgisse como um segundo operante paralelo e insubstituível na cura dessa patologia que também aflige a alma.

A cirurgia tem implicado uma concretização, e não mais uma idealização da cura. Enquanto a medicação impõe ao sujeito uma submissão a outros sintomas que potencializam os inúmeros conflitos, fragmentando a sua subjetividade, a cirurgia tem sido a chave para que esses conflitos sejam libertados e ressignificados.

Voltando ao ponto da escuta a que me propus fazer dos sujeitos do grupo (Kaës, 1997), as poucas histórias que tive a oportunidade e o privilégio de conhecer revelaram algumas particularidades significativas de um registro subjetivo. A fim de enriquecer este relato de experiência, apresentarei, a seguir, duas histórias bastante significativas de dois associados.

Pedro é um homem perto de seus 50 anos, que passou a vida inteira sendo medicado por causa de seus ataques. Teve que se aposentar muito cedo, e viu-se nas mãos daquela que não the permitia viver em liberdade. Em certos momentos de sua vida, chegou a tomar 
vinte e dois comprimidos para que as suas crises fossem controladas. Esses vinte e dois comprimidos não respondiam mais às condições que a epilepsia lhe impusera e muito menos serviam de contraponto para a sua sobrevivência. Certa época, aproximouse do suicídio por achar que não valeria a pena viver naquele aprisionamento. Ele queria a liberdade, que era sempre cultivada em seus momentos de esperança e bom humor nas reuniões. A sua história clínica mostrava um descompasso de opiniões entre profissionais e um desencontro na combinação da medicação, fruto da falta de informação e do tabu no meio médico.

Enquanto sabemos que, no Brasil, há duas grandes referências cirúrgicas e de tratamentos avançados em epilepsia, ainda hoje há grupos de profissionais que não conhecem o processo de cura da epilepsia através da cirurgia. Hoje, sabemos que $80 \%$ dos casos são tratáveis com a cirurgia, o que representa a condição de não mais conviver com a doença pelo resto da vida.

Foi o que aconteceu com Pedro. Ele fez a cirurgia após ter convivido mais de 40 anos com a epilepsia. Ausentou-se dela, finalmente. Porém, a sua história não estaria livre dela, mas permeada por ela. Aprender a viver sem ela e livre, apesar de ter passado por ela, foi o maior desafio de Pedro. Nos últimos encontros que tivemos, ele comentava como o seu corpo estava sendo desintoxicado dos remédios e como isso representava uma depuração, apesar de toda a condenação por longo tempo. O mal, aos poucos, estava sendo deixado de lado como um pequeno acessório da vida, e não enquanto estrutura central que alicerçou tanto tempo a sua subjetividade e que apagava aos poucos os sinalizadores auxiliares e saudáveis que alimentavam os seus projetos de vida.
Pedro está mais vivo do que nunca, movimentando-se em direções produtivas. Acredito que esteja celebrando intensamente a vida, apesar do acolhimento que esta fez da morte a todo instante.

Embora Freud (1979b) tenha nos dito que o sofrimento nos ameaça a partir de três direções, a do corpo, a do mundo externo e a do outro, e muito embora os epilépticos estejam fadados a essas fontes, a esperança foi algo não decifrado que alimentou Pedro durante essa jornada. Essa foi a marca subjetiva de Pedro. A esperança é um sentimento consciente, mas fruto de que causa? O enigma que todo o paradoxo nos lança aponta para a incrível distância e para as proximidades da dor e da esperança, fazendo desta um substitutivo satisfatório diante do caos.

Podemos colocar, também, a esperança como possibilidade de construção de uma subjetividade no caso de Cláudia. Cláudia, ex-portadora, que hoje coordena o trabalho da associação, apresentava um grande potencial psíquico apesar de todos os sofrimentos vivenciados. Ela me relatava fatos muito delicados e difíceis de sua vida, mas sempre regava o seu contexto com a palavra esperança. Ela disse, uma vez, que o seu projeto de ajudar os portadores representava o sofrimento transformado em compensação, ou seja, poder conduzir o outro ao tratamento de sua enfermidade. Também a cirurgia significou para ela um achado. "Os médicos acharam a chave de meu cofre" - disse ela. "Acharam a chave para a liberdade". Ela estava desimpedida do grande mal. Cláudia ausentou-se dele nos registros da consciência, mas ele estará presente nos registros de sua história inconsciente. Não só a sua história, mas a de outros, guardarão, sem dúvida, um grande enigma que ainda será estigmatizado pelas pessoas. 
Enfim, acreditamos que ainda temos poucas palavras para decifrar os grandes significados que o sofrimento, a ausência, o grande mal e o tempo de crise possam representar para o portador e ex-portador de epilepsia. O trabalho da associação representa o primeiro passo nesse processo. Precisamos escutar esses pequenos grupos. Eles significam o primeiro porto social para que as suas angústias sejam escutadas e o sofrimento ancorado. Acreditamos que mais trabalhos devam vir, no futuro, para aqueles que sejam portadores de alguma deficiência ou síndrome. No caso dos portadores da ASPEMG, senti que alguma coisa poderia ser feita. Então, passei a escutá-los, tomando cuidado para que a surdez não me atrapalhasse. Gostaria de alertar para o fato de que essa surdez dos profissionais de saúde acerca dos portadores deve ser discutida a fim de que haja o avanço desse estudo num futuro próximo. Confirmamos que os progressos da Medicina contribuíram para a libertação do epiléptico de suas crises, contudo, a sua libertação será conquistada em sua plenitude quando o portador se reconhecer enquanto sujeito desejante e cidadão que reivindica um lugar a ser ocupado na sociedade. 


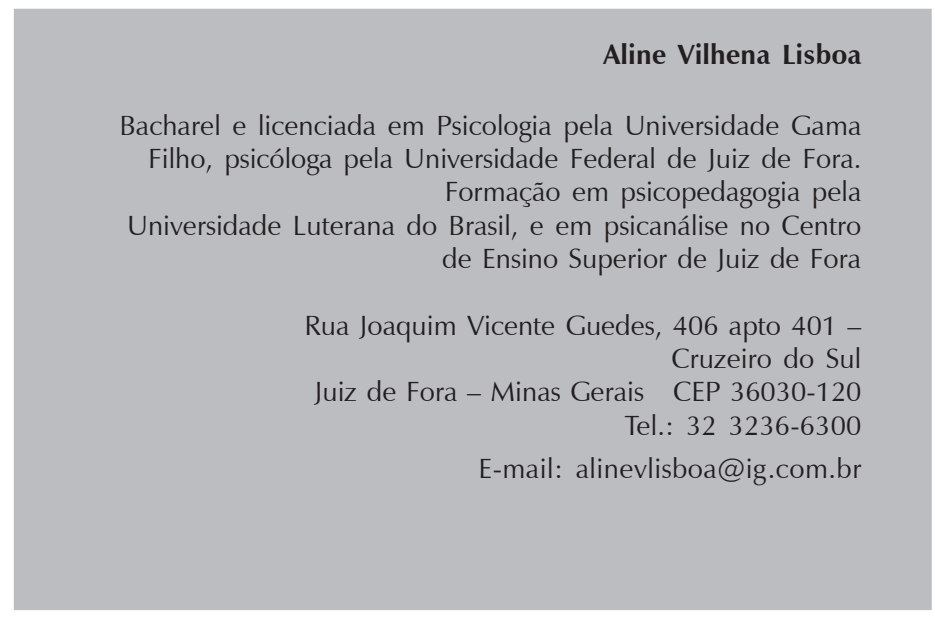

Recebido 28/04/03 Reformulado 30/12/04 Aprovado 10/04/05

BIRMAN, Joel. O Mal-estar na Atualidade: a Psicanálise e as Novas

Formas de Subjetivação. Rio de Janeiro: Civilização Brasileira, 2001.

FREUD, S. O Ego e o Id. In Edição Standard das Obras Psicológicas

Completas de Sigmund Freud, v. II. Rio de Janeiro, Imago, V, XIV, 1979a.

O Mal-estar na Civilização. In Edição Standard

das Obras Psicológicas Completas de Sigmund Freud, v. II. Rio de Janeiro, Imago, V, XXI, $1979 b$.
. Os Instintos e suas Vicissitudes. In Edição Standard

\section{Referências}

